\title{
米 \\ MÍDIA, ARTE E PODER: EMBATES E CONTROLE DE IMAGEM
}

Resenha do artigo: MIKLOS, Jorge; PENNA, T. No Interlúdio da Imagem: Iconoclastia e Iconofagia no Neopentecostalismo Brasileiro. LUMEN ET VIRTUS, v. IX, p. 88-114, 2018.

\section{- ALDONES NINO ${ }^{1}$}

1 Doutorando em Historia y Arte pela Escuela Internacional de Posgrado de la Universidad de Granada (UGR) em cotutela com o Programa de Pós Graduação em Artes Visuais da Escola de Belas Artes da Universidade Federal do Rio de Janeiro. E-mail: aldones.c@gmail.com

Recebido em: 25/10/2019

Aprovado em: 28/10/2019

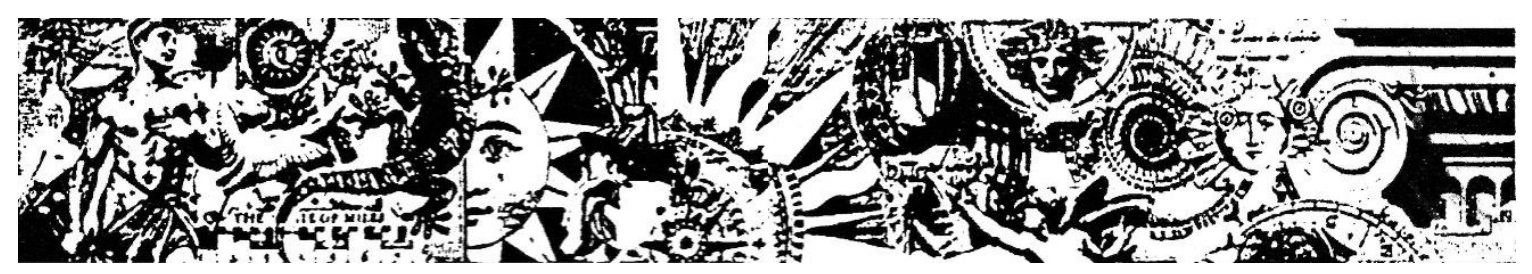

Tornou-se uma das questões cruciais da sociedade brasileira atual o avanço da relação entre as igrejas neopentecostais e as redes de comunicação de massa, fato que vem ganhando cada vez mais protagonismo no campo das artes visuais. Em uma disputa cada vez mais acirrada, artistas e fiéis discutem o tensionamento das possibilidades de usos de imagens religiosas. Variadas contribuições sobre o modo como essas questões atravessam nosso presente podem ser encontradas nos antecedentes históricos da relação entre imagem, arte e religião. 0 artigo No Interlúdio da Imagem: Iconoclastia e Iconofagia no Neopentecostalismo Brasileiro, publicado no $\mathrm{n}^{\circ}$ 23 da Revista Lumen et Virtus (dez/2018) pelo Prof. Jorge Miklos e pela Profa. Tatiana Penna, aponta como o neopentecostalismo midiático moldado na sociedade do espetáculo e do entretenimento passa a incorporar técnicas oriundas dos meios de comunicação massiva com foco no amplo alcance da difusão tecnológica de seus produtos², um dos elementos centrais da série de pinturas da Mitomania (2016) de Lucas Lugarinho e do também do filme Terremoto Santo (2017) de Bárbara Wagner \& Benjamin de Burca.

\footnotetext{
2 Para mais detalhes ver: SOUZA, André Ricardo de. O empreendedorismo neopentecostal no Brasil. Ciencias Sociales y Religión, v. 13, p. 13-34, 2011.
} 
Trabalhos como a série fotográfica Ecléticos, de Marcos Chaves (2001) e a pintura Cruzando Jesus Cristo com o Deus Shiva (1996) de Fernando Baril colocaram no centro do debate a apropriação de imagens vinculadas ao universo religioso e a produção artística. A polêmica envolvendo a exposição Queermuseu (2017) apenas evidenciou questões latentes tensionadas por eventos anteriores, vide exemplo, Desenhando em Terços (2005) de Márcia X, obra retirada da exposição no CCBB-RJ em 2006 ou pela onda de fúria enfrentada por Antônio Obá, na realização do trabalho Atos da transfiguração: receita de como fazer um santo (2015), que resultou no auto-exílio do artista após perseguições e ameaças de morte. Enquanto no período barroco a retórica teve grande preponderância no discurso artístico, em prol dos interesses religiosos, na contemporaneidade a arte possibilita o hackeamento dessas composições imagéticas. Esses são apenas alguns episódios de grande repercussão nacional que apontam para a importância do debate acerca do status das imagens religiosas e seus usos na cena cultural midiática contemporânea.

Miklos e Penna apontam a necessidade de perceber como os fenômenos contemporâneos são irrigados por rizomas mais profundos, diacronicamente e sincronicamente, e que não aparecem na superfície (MIKLOS; PENNA, 2018, p. 91). Os autores indicam como essa nova cultura visual religiosa no neopentecostalismo atravessa um contexto sociocultural de midiatização do imaginário religioso. 0 artigo afirma que a base teórica para pensar esse tema não é a História da Arte (Idem). Compreendo, contudo, que a história da arte é um campo autônomo de conhecimento com especificidades centradas nas questões da arte e da visualidade, um campo híbrido capaz de apresentar teses que tenham como um dos pilares a riqueza epistemológica e o relacionamento com várias disciplinas 3 . 0 artigo aponta para o crescimento da importância do movimento pentecostal independente após a década de 1990, e faz o uso do termo cultura gospel, que teve seu processo de formação abordado por Magali do Nascimento Cunha em sua Tese de doutorado em Comunicação, defendida na Escola de Comunicação e Artes da Universidade de São Paulo em 20044.

Partindo da análise de perspectivas de três tradições religiosas monoteístas (judaísmo, cristianismo e islamismo), o artigo recupera precedentes históricos relacionados ao debate entre imagem e idolatria. Por este prisma a reflexão apoia-se nos estudos acerca dos processos iconofágicos da cultura e de suas interferências no cenário religioso (MIKLOS; PENNA, 2018, p.

\footnotetext{
3 Vide: Projeto Pedagógico do Curso de História da Arte elaborado pelo Departamento de História e Teoria da Arte da Escola de Belas Artes da Universidade Federal do Rio de Janeiro (2017).

${ }^{4}$ CUNHA, Magali. Vinho novo em odres velhos: um olhar comunicacional sobre a explosão gospel no cenário religioso evangélico no Brasil. São Paulo, 2004. Tese (Doutorado em Comunicação). Escola de Comunicação e Artes, Universidade de São Paulo, São Paulo, 2004.
} 
91), fundamentados em teóricos como Mircea Eliade, Joseph Campbell, AbyWarburg, Günter Gebauer, Christoph Wulf, Edgar Morin, Hans Belting, entre outros. Considerando processos de iconoclastia e idolatria, é possível acrescentar que as imagens não apenas vivem mais, como criam estratégias culturais de sobrevivência, perpetuando-se sob as mais diversas e insuspeitas formas (MIKLOS; PENNA, 2018, p. 95). No decorrer do texto ficam evidentes as implicações referentes à questão do uso das imagens, ora assimilando, ora negando sua potencialidade em um constante vai e vem. Os autores passeiam por diversos episódios que reiteram o resgate do simbolismo religioso, explorando novas modalidade de imagem e experiência religiosa contemporânea, extrapolando os limites nacionais, vide os exemplos elencados da manifestação do Papa João Paulo II, líder mundial da Igreja Católica, em 12 de outubro de 1995, quando o bispo Sérgio Von Helder da Igreja Universal do Reino de Deus, em programa televisivo O Despertar da Fé, transmitido pela Rede Record (emissora pertencente a Universal), destrói uma imagem de Nossa Senhora Aparecida, considerada pelos católicos a padroeira do Brasil.

Um dos principais destaques do texto é a eficiência com o qual articula referências de tempos e geografias distintas, abordando desde imagens presentes nas Catacumbas de Santa Priscila, em Roma (Sec. II), até a performance da atriz Viviany Beleboni na $19^{\circ}$ edição da Parada do Orgulho LGBT de São Paulo (2015), como também o trágico desfecho resultante da publicação de charges no jornal francês Charlie Hebdo, estopim para o massacre ocorrido em 7 de janeiro de 2015, em Paris, resultando na morte de doze pessoas pela Al-Qaeda da Península Arábica (AQPA).

O artigo demonstra de que modo uma abordagem transdisciplinar à história da arte poderia contribuir com 0 avanço de pesquisas que teçam aproximações entre religiosidades contemporâneas e as novas práticas do mundo virtual e midiático. Os autores consideram não apenas os usos da imagem em seu contexto sacro, mas também de resistência e insubordinação, enunciando uma reorganização no estatuto de criação e circulação de imagens. Como nos trabalhos desenvolvidos pelas artistas Ventura Profana, Tabernáculo da Edificação (2019) e A Cristalização de Brasília (2019) de Guerreiro do Divino Amor e nas reapropriações imagéticas presentes nos trabalhos da Fudidasilk - um coletivo-cooperativa de serigrafia formado por artistas estudantes da Escola de Belas Artes da Universidade Federal do Rio de Janeiro (UFRJ). A cada dia surgem novas elaborações acerca da cultura neopentecostal e da atualização de suas estratégias, em especial, porque, para difundir seus produtos e propostas de mundo, essas instituições utilizam suportes técnicos, investindo significativamente em meios midiáticos para propagação de suas marcas (MIKLOS; PENNA, 2018, p. 112). 
Fica claro no decorrer do texto que o significado da imagem religiosa na cena cultural contemporânea engendra discursos carregados de sentidos controversos, indo desde ameaça à integridade física de artistas, até mesmo a atentados terroristas. A eclosão de estudos e propostas artísticas que abordem o debate em torno do neopentecostalismo vai ao encontro dos debates acerca das estruturas mentais de adeptos de segmentos religiosos no Brasil, já que preceitos vinculados a predestinação divina e ao sagrado reverberam no mundo político, em especial na democracia 5 .

\footnotetext{
${ }^{5}$ Para mais detalhes ver: COPELLI, Giancarlo Montagner. Neopentecostalismo e democracia no Brasil: Entre os eleitos de Deus, há espaço para os iguais da democracia? Revista Jurídica Direito, Sociedade e Justiça, v. 1, p. 1-17, 2014.
} 